\title{
LA RELEVANCIA DEL PORMENOR NARRATIVO EN LOS DÍAS DEL ARCOÍRIS DE ANTONIO SKÁRMETA
}

\author{
THE RELEVANCE OF THE NARRATIVE DETAIL IN THE DAYS OF \\ THE RAINBOW BY ANTONIO SKÁRMETA
}

\author{
Pablo Fuentes Retamal \\ Universidad de Concepción - Chile \\ pfuentesr@udec.cl
Yasna Burich OYarzún
Universidad de Concepción - Chile
yasnaburicho@gmail.cl

\begin{abstract}
Resumen: Este artículo propone una lectura de Los días del arcoíris (2011) de Antonio Skármeta, a partir del estudio de las catálisis o pormenores de la narración. Estas unidades mínimas están repletas de significación y sentido, pues establecen puntos de anclaje que articulan el relato a nivel político, simbólico e ideológico. En detalles tan ínfimos como las prendas que visten los personajes, los colores que pintan el relato, los objetos que decoran el espacio diegético, entre otros, no sólo se halla la presencia del poder, sino que también indicios de un contexto histórico que subyace en los acontecimientos narrados.
\end{abstract}

Palabras clave: Antonio Skármeta, literatura chilena, catálisis, detalles, dictadura de Pinochet.

\begin{abstract}
This article suggests an interpretation of The Days of the Rainbow (2011) by Antonio Skármeta, from the catalysis or narration details. These minor components are full of significance and sense, because they establish anchor points that articulate the text at a political, symbolic, and ideological level. Thus, in very negligible aspects such as the pieces of clothing worn by the characters, the colours that depict the story, the objects that decorate the narrative space, among others, not only can we find power but also a historical context hidden in the narrated events.
\end{abstract}

Keywords: Antonio Skármeta, Chilean literatura, catalysis, details, Pinochet's dictatorship.

Recibido: 22/08/18. Aceptado: 12/03/2019. 


\title{
Introducción
}

\begin{abstract}
Pinochet había tenido el total control de los medios durante quince años [...] a él le daban quince minutos, quince minutitos, un puñado de segundos para fracturar de una vez al sólido panzer de la dictadura.
\end{abstract}

Antonio Skármeta, Los días del arcoíris.

\begin{abstract}
A ntonio Skármeta describe en su narrativa la contingencia histórica chilena de las últimas cuatro décadas. Las primeras novelas del autor $-E l$ entusiasmo ${ }^{1}$ (1967), Tiro libre ${ }^{2}$ (1973) y Soñé que la nieve ardía ${ }^{3}$ (1975)retratan sucesos anteriores al Golpe de Estado, vale decir las reformas sociales del Presidente Frei Montalva, la articulación de la Unidad Popular y el gobierno del Presidente Salvador Allende. Las novelas posteriores de este escritor -No pasó nada ${ }^{4}$ (1980), La insurrección ${ }^{5}$ (1982) y Ardiente paciencia $^{6}$ (1985) - describen acontecimientos en el marco del Golpe de Estado, es decir la dictadura de Augusto Pinochet, la vida de los chilenos en el exilio y las repercusiones de la revolución nicaragüense (Epple, p. 110). El relato más reciente del autor, Los días del arcoíris (2011), se incorpora a esta última triada novelesca.

El argumento de Los días del arcoíris retrata las implicancias acontecidas durante el Plebiscito de 1988, un referéndum cuyo propósito fue determinar la continuidad de Augusto Pinochet en el poder. El relato aborda estos comicios desde dos perspectivas:
\end{abstract}

${ }^{1}$ Los relatos que conforman El entusiasmo son: "La cenicienta en San Francisco", "El joven con el cuento", "Al trote", "Entre todas las cosas lo primero es el mar", "Días azules para un ancla", "Nupcias", "Relaciones públicas" y "Mira donde va el lobo".

${ }^{2}$ Tiro libre reúne los siguientes cuentos: "Pecado", "El último tren", "Uno a Uno", "Primera preparatoria", "Enroque", "Balada para un gordo", "El cigarrillo", "París y Profesionales".

${ }^{3}$ Soñé que la nieve ardía relata los últimos meses de la Unidad Popular desde la perspectiva de Arturo, un muchacho que se muda a Santiago con pretensiones futbolísticas, pero que termina participando en la Unidad Popular.

${ }^{4}$ No pasó nada describe los esfuerzos de Luis por incorporarse a las oportunidades que ofrece Berlín a los exiliados. Este relato tiene matices autobiográficos, pues Skármeta se refugió en Alemania Occidental tras el Golpe de Estado.

${ }^{5}$ La insurrección se sitúa en Nicaragua, específicamente en la ciudad de León durante la revuelta sandinista.

${ }^{6}$ Ardiente paciencia pormenoriza la vida de Mario Jiménez, un joven cartero que cambia los aperos de pescador por una nutrida correspondencia dirigida al poeta Pablo Neruda. 
La de Nico, cuyo padre es un profesor de filosofía que es detenido y sacado desde la sala del Instituto Nacional donde impartía clases, entre otros, a su propio hijo; y la de Adrián Bettini, un publicista cesante a quien se le encomienda realizar la franja electoral televisiva del "No". (O.S., p. 162)

Antonio Skármeta señala que el Plebiscito de 1988 fue un acontecimiento cautivante, por esto se propuso trabajar artísticamente estos comicios desde que fueron convocados: "es una cosa que me sorprendió muy fuerte y pensé que sería un tema como para exponerlo internacionalmente" (cit. en Soto, 2013, p. 26). El escritor proyectó este interés en la obra radial Das nein (El no) ${ }^{7}$, el montaje teatral El plebiscito $^{8}$ y la novela Los días del arcoíris. Skármeta indica que este relato presenta una complejidad artística mayor, pues aborda el Plebiscito de 1988 y la contingencia política de la época, por ejemplo "la represión a estudiantes y alumnos en los colegios en los tiempos de la dictadura" (cit. en Soto, 2013, p. 26).

La crítica literaria mantiene una deuda con Los días del arcoíris, pues la lectura de Grínor Rojo es la única para este relato. Este trabajo indica que la novela describe una pequeña historia de los entretelones del Plebiscito de 1988. Un relato capaz de explicar "cómo el presente chileno es un producto de aquel pasado” (Rojo, 2016, p. 246). Este diálogo lo posibilita una trama narrativa que combina "dos historias de diferente temple y cuyas narraciones se alternan y a la larga se fusionan" (Rojo, p. 237). El publicista Adrián Bettini interpreta uno de estos carriles narrativos, mientras el estudiante Nicómaco Santos ${ }^{9}$ lidera el segundo sintagma narrativo. Estas tramas se fusionan en los capítulos finales de la novela, fundando una utopía de armonía, entendimiento, amor y paz universal (Rojo, p. 248).

La reflexión de Grínor Rojo indica que Los días del arcoíris es una novela "irónica que, a escala microscópica, replica la tan discutible y tan discutida comedia del «No»" (Rojo, p. 248). Estimamos provechosas estas palabras, pues anuncian la posibilidad de comprender la novela de Skármeta

Skármeta dirigió y estrenó esta obra radial en Alemania.

${ }^{8}$ Los guionistas de la película No (2012) emplearon los parlamentos de El plebiscito para dar forma a la acción cinematográfica.

9 El nombre de este personaje es Nicómaco, aunque prefiere ser llamado "Nico". El origen de este nombre se debe al interés del padre de Nicómaco por la filosofía aristotélica, especialmente por el tratado titulado Ética a Nicómaco (Skármeta, 2013, p. 54). 
mediante una lectura que atienda los aspectos mínimos de la narración. Esta propuesta crítica dialoga con las declaraciones que expresó Antonio Skármeta en Conversaciones con la narrativa chilena (1991). El autor precisa en este diálogo con Juan Andrés Piña cómo inciden sus experiencias vitales en el ejercicio escritural:

Para mí, la vivencia del barrio fue determinante, porque tuve la experiencia de pertenecer a una pandilla, a una patota, con todos sus valores, sus bibliotecas, su tráfico de revistas.

[...]

Todo ese mundo pleno fue clave en mi escritura posterior, por el siguiente tema estético: en mis relatos aparece habitualmente la totalización de un universo en un microcosmos. (cit. en Piña, 1991, p. 160)

Es interesante que el trabajo de Grínor Rojo y el testimonio de Antonio Skármeta sugieran una misma posibilidad de estudio: la convocatoria de un contexto en los aspectos mínimos del relato. Esta convergencia propicia el objetivo que acoge este artículo, cuyo propósito es estudiar los pormenores narrativos en Los días del arcoíris para determinar los puntos de anclaje que sostienen los valores temáticos, políticos, simbólicos e ideológicos que sugiere la narración.

Recordemos que Roland Barthes distingue en El efecto de realidad (1968) dos unidades en el relato: las denominadas "funciones cardinales", que constituyen las verdaderas bisagras del relato, y las llamadas "catálisis”, que completan los espacios vacíos entre aquellas funciones primeras (Barthes, 1987, p. 179). A simple vista, pareciera que las catálisis no son más que detalles, en apariencia inútiles, que sólo elevan el coste de la información narrativa; sin embargo, tales anotaciones son relevantes, pues otorgan verosimilitud a la narración. Barthes cita un fragmento de $U n$ corazón sencillo de Gustave Flaubert para demostrar la preponderancia de las catálisis, puntualmente aquel pasaje del relato que describe la sala de madame Aubain: "Un pequeño vestíbulo separaba la cocina de la sala donde madame Aubain se pasaba el día entero, sentada junto a la ventana en un sillón de paja [...]. Un piano viejo soportaba, bajo un barómetro, una pirámide de cajas y cartones" (cit. en Barthes, p. 186).

Aquel piano, barómetro, cajas y cartones no cumplen otra función más que señalar: "nosotros somos lo real" (Barthes, p. 186). En síntesis, aque- 
llos "detalles en apariencia inútiles" son aspectos de máxima consideración para el relato, pues aportan unidades de verosimilitud que denotan directamente lo real.

Michel Foucault se refirió a la importancia de los detalles en Vigilar y castigar (1975). Este filósofo indica que "la mecánica del poder" concibe en los pormenores una acumulación de procesos minúsculos que convergen en beneficio de un diseño mayor (2002, p. 136). De esta manera, para describir una microfísica es necesario fijar la atención en detalles y minucias que, mediante un funcionamiento coherente y organizado, aportan sentido a lo ínfimo e insignificante.

La reflexión de Hayden White constituye el tercer pilar teórico que ilumina nuestra lectura. Este filósofo de la historia revitalizó la conceptualización del discurso historiográfico proponiendo que una misma secuencia histórica puede tramarse desde diferentes perspectivas. De este modo, la narración histórica es el resultado de la sutileza del historiador en la elaboración de una trama ${ }^{10}$ específica para aquellos episodios a los que adjudica "un tiempo especial de significado" (White, 2003, p. 115).

Los principios teóricos de White establecen vínculos profundos entre Historia y Literatura al mostrar la base lingüística sobre la que se articula la obra histórica (1992, p. 10). En este sentido,

ningún conjunto dado de acontecimientos históricos casualmente registrados puede por sí mismo construir un relato [...]. Los acontecimientos son incorporados en un relato mediante la supresión y subordinación de algunos de ellos y el énfasis en otros, la caracterización, la repetición de motivos, la variación del tipo y el punto de vista, las estrategias descriptivas alternativas y similares; en suma, mediante todas las técnicas que normalmente esperaríamos encontrar en el tramado de una novela. (White, 2003, p. 113)

Los acontecimientos descritos en un relato histórico no cambian sustancialmente de un texto a otro. Lo que difiere son las "modalidades y las relaciones que el historiador establece entre estos sucesos" (White, 2003, p. 134). En pocas palabras, lo que pretende White es poner en evidencia los

\footnotetext{
${ }^{10}$ Según White, el "tramado" es la manera en que una "secuencia de sucesos organizados se revela de forma gradual como un relato de cierto tipo particular" (1992, p. 17).
} 
fundamentos literarios sobre los que se construye el relato histórico.

La metodología de trabajo de este artículo estudia, en primer lugar, a la trama narrativa que protagoniza el publicista Adrián Bettini. Luego se analizan los sucesos narrativos interpretados por el estudiante Nico Santos. Como ya se dijo, los capítulos finales de Los Días del arcoíris convocan a ambos personajes en un mismo espacio diegético, por consiguiente, la reflexión que corresponde a estos pasajes del relato consideran a Bettini y a Santos en una misma instancia de estudio.

\section{Un análisis del pormenor narrativo en la trama narrativa que protagoniza el publicista Adrián Bettini}

Las primeras páginas de Los días del arcoíris describen a un par de agentes notificando al publicista Bettini para asistir a una reunión con el Ministro Fernández"1: "recibió una carta. No la traía el cartero del barrio sino dos funcionarios jóvenes con insignias de policías bajo la solapa que tocaron brevemente el timbre" (Skármeta, 2011, p. 13). Estos funcionarios policiales no ocultan sus placas identificatorias gratuitamente, por el contrario, este pequeño gesto revela el funcionamiento del poder en las sociedades disciplinarias. Michael Foucault señala que las disciplinas adquieren mayor efectividad cuando operan desde el anonimato, pues así promueven en la ciudadanía una "conciencia inquieta de ser observados" (p. 187).

Estos comisionados del poder sorprenden a Bettini vestido con una "desteñida casaca de lana" (Skármeta, 2013, p. 13). Este atuendo parece ser un detalle irrelevante, sin embargo, aquella prenda adquiere importancia al contrastarse con la tenida del protagonista en su cita con Fernández.

El narrador describe a un temeroso Adrián Bettini ingresando a la oficina del ministro Fernández, el hombre "más duro del régimen luego de Pinochet” (Skármeta, 2013, p. 19). El aspecto del publicista en esta reunión es significativo, pues demuestra que el poder se vale de técnicas minuciosas e ínfimas para fabricar "cuerpos dóciles" (Foucault, 2002, p. 195): "El señor

${ }^{11}$ Este sujeto novelesco remite a la ficcionalización de Sergio Fernández (1939- ). Ministro del Trabajo y del Interior durante la dictadura militar. 
Bettini desenterró de un baúl una corbata y se la anudó sin alegría frente al espejo" (Skármeta, 2013, p. 19).

El protagonista reemplazó la "desteñida casaca de lana” que vestía al inicio de las acciones narrativas por una "corbata", atuendo que sólo cumple funciones estéticas y de ornamento a la camisa. Los gestos de Adrián Bettini ante el Ministro Fernández evidencian los efectos del poder, pues el publicista acicala su chaqueta para limpiar cualquier salpicadura que le reste pulcritud, además palpa el nudo de su corbata para comprobar su prestancia ante el poder:

Bettini se frotó la solapa como si tuviera una mancha de ceniza. Estar discutiendo con el ministro del Interior le comenzaba a dar un inesperado aplomo.

[...]

Bettini se puso de pie y palpó el nudo de la corbata para ocultar el salto de su nuez de Adán cuando tragó abruptamente la saliva agolpada en su lengua. (Skármeta, 2013, pp. 20-5)

Los esfuerzos de Adrián Bettini por lucir "disciplinadamente" contrastan con la naturalidad que proyecta el ministro Fernández. El narrador describe a este líder del régimen militar "con una dentadura perfecta" mientras se balancea en "un sillón giratorio" (Skármeta, 2013, p. 21).

La dentadura impecable del Ministro Fernández es un detalle que, en palabras de Foucault, evidencia el "disciplinamiento de las cosas pequeñas" (2002, p. 143). Un pormenor en apariencia irrelevante pero capaz de señalar que las disciplinas promueven la sujeción y el control de las menores partículas del cuerpo. El sillón giratorio que ocupa el ministro Fernández también es significativo, especialmente si consideramos que este objeto cumple funciones panópticas. El sillín giratorio, ubicado al centro de la oficina, ocupa un espacio similar al de torre central en el edificio panóptico (Bentham, 1989, p. 36). Por consiguiente, el asiento del Ministro Fernández es un recurso alegórico que remite al funcionamiento del poder en los regímenes totalitarios.

El ministro Fernández concertó esta reunión para ofrecer a Bettini la dirección de la franja política del «Sí». Esta oferta laboral suscita el siguiente diálogo: 
[...] Bettini, ¿Qué me dice?

- ¿Qué le digo? Le digo que dicen que nada de lo que sucede en este país escapa a su conocimiento.

- Oh, sí. He oído esa exageración.

- Dicen que no se mueve una hoja sin que usted lo sepa. (Skármeta, 2013, p. 24)

A simple vista, podríamos pensar que la expresión "no se mueve una hoja sin que usted lo sepa" es parte de un diálogo contextualizado en el desarrollo de las acciones narrativas; sin embargo, tras aquella afirmación se esconde una referencia directa a las declaraciones de Augusto Pinochet. El historiador Carlos Huneeus señala que el dictador concentró tantas funciones institucionales y políticas durante su mandato que reunió la potestad necesaria para dirigirse a los chilenos y advertirles: "aquí no se mueve una hoja sin que yo lo sepa" (Huneeus, 2000, p. 36).

Cuando el narrador de Los días del arcoíris incorpora a la diégesis referencias textuales a las declaraciones de Augusto Pinochet, establece diálogos entre la historiografía y sus fundamentos literarios. Las bodas que celebran Historia y Literatura en el relato de Skármeta demuestra que "hay un elemento de historia en toda poesía, y también un elemento de poesía en cada relato histórico" (White, 2003, p. 136).

La sala que cobija la reunión que sostienen Fernández y Bettini presenta una decoración que revela el funcionamiento del poder. Los cuadros que ornamentan esta habitación son opacados por el retrato, a todo color, de Augusto Pinochet. Así lo advierte el protagonista cuando señala: "había una foto en colores del dictador y ningún otro cuadro que compitiera con su presencia" (Skármeta, 2013, p. 29). Este pormenor narrativo dialoga con la reflexión de Michel Foucault respecto de la decoración del edificio panóptico, cuyas paredes portan mensajes, por ejemplo, la sentencia "Dios os ve" (2002, p. 273). En este sentido, el retrato de Augusto Pinochet en el espacio novelesco es un símbolo que opera sobre la moral de los personajes para encauzar la conducta.

El Ministro Fernández, tras conocer la negativa de Bettini a dirigir la franja política de Pinochet, se dirige a la ventana para desplazar "la cortina" (Skármeta, 2013, p. 30). Este acto evidencia el hermetismo en que se sos- 
tuvo la reunión, de modo que los visillos cerrados garantizan al poder que ningún intruso conozca sus intenciones.

Las cortinas son pormenores narrativos que figuran en relatos anteriores de Skármeta. La novela No pasó nada describe a un grupo de chilenos desterrados en Berlín. Estos exiliados lamentan que sus habitaciones carezcan de persianas, pues estas celosías les otorgarían privacidad a sus reuniones:

La familia se había reunido en una asamblea plenaria en la cocina. [...] Para colmo era un día de esos luminosos, y como nunca hemos tenido dinero para comprar cortinas, las cosas brillaban, y los vidrios parecían llamaradas. (Skármeta, 1989, p. 34)

Volviendo a Los días del arcoíris, el publicista Bettini se retira de la oficina de Fernández y aborda un automóvil conducido por Magdalena, su esposa. La conducción de esta mujer evidencia los efectos del poder sobre los individuos: "aunque no había luz roja en el semáforo, Magdalena detuvo el coche ignorando los bocinazos de los autos que protestaban a sus espaldas. [...] Los bocinazos arreciaban y Magdalena hizo partir el coche de un brusco salto" (Skármeta, 2013, pp. 37-8).

El semáforo es un dispositivo que ejerce funciones panópticas, pues opera desde el anonimato, evidenciando que en la sociedad disciplinaria los más mínimos movimientos están regulados. Siguiendo los planteamientos de Foucault en Vigilar y castigar, indicamos que la persistencia de Magdalena a permanecer detenida frente a un semáforo en verde es muestra de la docilización que subyugó al pueblo chileno durante la dictadura militar.

El narrador skarmetiano se refirió al semáforo, en cuanto dispositivo disciplinario, en Ardiente paciencia. El narrador de este relato describe al diputado Labbé prometiendo un semáforo a sus electores para disciplinar a los escasos automovilistas que circulan por el sector:

Lentamente se iba acercando a cumplir su juramento como constaba con la inauguración de un desconcertante semáforo - aunque con los tres colores reglamentarios- en el cruce de tierra por donde transitaba el camión que recogía pescados, la bicicleta de Mario Jiménez, burros perros y aturdidas gallinas. (Skármeta, 1985, p. 41) 
Retomando Los días del arcoíris, señalamos que Olwyn ${ }^{12}$, personaje que lidera la oposición a Pinochet, ofrece al protagonista dirigir la campaña del «No». El publicista acepta esta responsabilidad en honor a sus convicciones políticas, pues este trabajo no es remunerado. El músico Raúl Alarcón, alías Florcita Motuda ${ }^{13}$, ingresa a las acciones narrativas para componer las melodías que acompañan a esta franja política. La descripción de este músico es provechosa para nuestra lectura:

El hombrecito [...] poseía una cabellera hirsuta que lo elevaba diez centímetros por encima de su frente y un par de lentes gruesos enmarcaban los vidrios de sus anteojos. El bigote le caía desordenado sobre sus labios, y parecía que ningún pelo rimaba con otro. (Skármeta, 2011, p. 79)

El cabello hirsuto y los bigotes caóticos de Motuda son pormenores narrativos que exteriorizan la rebeldía de este personaje. Estos rasgos descriptivos contrastan con los atributos que el narrador puntualizó para los agentes de la dictadura, vale decir sujetos disciplinados de "pelo corto y bien afeitados" (Skármeta, 2011, p. 15). Las prendas que Motuda viste acreditan su disidencia, una chaqueta gastada cubierta con manchas y un pañuelo sucio son pormenores narrativos que articulan los valores temáticos e ideológicos que sugiere la narración:

Su atuendo no le iba a la zaga: un traje negro pulido por los años destellaba por aquí y allá contrastando con algunas manchas de vino o kétchup.

El hombre carraspeó limpiándose al mismo tiempo la frente con un pañuelo gris. O un pañuelo que alguna vez había sido blanco. (Skármeta, 2013, pp. 79-80)

Aquellos personajes que filmaron la propaganda del «No» se reúnen en casa de Bettini para sintonizar la emisión de la franja política. El canal que

${ }^{12}$ El narrador pensó el nombre "Olwyn", a partir del apellido de don Patricio Aylwin (1918-2016). Político que colaboró en la campaña del «No» y que tras el retorno de la democracia fue Presidente de la República de Chile (1990-1994).

${ }_{13}$ Raúl Florcita Alarcón Rojas (1945- ). Músico chileno que compuso la música para la franja electoral del «No». Actualmente desempeña el cargo de diputado. 
escogen estos televidentes evidencia cómo operó la censura en la dictadura: "Adrián mira de reojo la cuenta regresiva para la publicidad de las campañas que marca el reloj electrónico del Canal 13” (Skármeta, 2011, p. 168).

Las casas televisivas de importancia durante la dictadura de Pinochet fueron Televisión Nacional de Chile (canal 7), en manos del Estado, y la red de la Universidad Católica (canal 13), a cargo de los rectores delegados de la casa de estudios. Canal 7 fue la señal que sirvió de portavoz y caja de resonancia a las verdades oficiales del régimen, mientras que la red universitaria tuvo un control editorial asegurado por las autoridades académicas (Durán, 2012, p. 12). Esta breve contextualización de los medios informativos en dictadura explica por qué Bettini y sus colegas sintonizan el canal 13 para ver la propaganda política. Un pormenor narrativo que articula los valores ideológicos de la narración, demostrando que los contenidos históricos pueden permanecer soterrados o escondidos en el texto literario (White, 2003, p. 112).

Un auto de color gris se estaciona frente al domicilio de Adrián Bettini mientras se emite la franja electoral del «No». La misma situación se repite en el apartamento de Florcita Motuda donde aparca un auto de color negro:

El acompañante del hombre del coche gris descendió y cruzando la calle fue hacia la puerta de la casa de Bettini y miró el número. Luego lo comparó con el que tenía escrito en una libreta y levantó el pulgar indicándole al chofer que estaba okey. (Skármeta, 2013, p. 189)

Florcita Motuda [...] volvió a mirar con preocupación ese auto negro que se había estacionado un poco más arriba de su departamento, cerca de la plaza. (Skármeta, 2013, p. 191)

Como ya dijimos, la individualización es descendente en los regímenes disciplinarios, vale decir el poder adquiere mayor funcionalidad en la medida que asume anonimato (Foucault, 2002, p. 178). De acuerdo con esta observación, el narrador colorea con gris y con negro los automóviles que transportan a los vigilantes de Bettini y Motuda, pues estas tonalidades permiten a sus tripulantes custodiar sin ser vistos. Los automóviles pintados con tonalidades oscuras son pormenores narrativos que se distinguen en novelas anteriores de Skármeta. El autor utilizó estas catálisis en Ardiente paciencia, puntualmente en aquellos pasajes del relato que descri- 
ben a los agentes de la dictadura que van tras los pasos del poeta Neruda:

Hacia las cinco de la madrugada, oyó frenar autos ante la puerta. [...] alguien que asomaba la cabeza por la ventana de uno de los dos autos sin patente.

$[\ldots]$

El joven del impermeable no tocó a Mario. Sólo se limitó a indicarle la dirección del Fiat negro. (Skármeta, 1985, pp. 131-2).

Continuando con el análisis de Los días del arcoíris, indicamos que los vigilantes apostados en el domicilio de Bettini muestran comportamientos afines a los requerimientos del poder. El narrador señala que estos funcionarios durante el día "escuchan música, comen naranjas, fuman y se turnan para ir de compras"; mientras que en la noche "tienen prohibido encender cigarrillos" (Skármeta, 2013, p. 197). Esta rutina de observación responde a principios militares, pues una simple llamarada es suficiente para alertar acerca de la presencia y la posición de un vigilante apostado en la oscuridad. Por consiguiente, el celador debe mimetizarse con su entorno y propiciar un camuflaje que le permita "confundirse con el ambiente, eclipsarse a la vista, ocultarse modificando las apariencias" (Lozano, 2008, p. 5).

\section{Un análisis del pormenor narrativo en la trama narrativa que protagoniza el estudiante Nico Santos}

Las acciones narrativas que protagoniza Nico Santos son articuladas por una misma nomenclatura léxico-semántica. La investigadora Luz Pimentel denomina "pantónimo" a este recurso narrativo, un procedimiento que desencadena estrategias de retrospección y prospección para asegurar, mediante su memorización permanente, la legibilidad del texto (Pimentel, 2001, p. 25). Este recurso narrativo explica las referencias permanentes a objetos de índole invernal, por ejemplo, las prendas que viste el protagonista: "Yo me pongo sobre el uniforme una chaqueta de cuero negro. Las gotas resbalan en la piel y no alcanzan a mojarme" (Skármeta, 2013, p. 9). El profesor Rodrigo Santos, padre del protagonista, también viste atuendos invernales: "un impermeable claro, color beige, como los de los detectives en las películas" (Skármeta, 2013, p. 9). El espacio que habitan padre e hijo 
está decorado con objetos de corte invernal: "hace frío y no está enchufada la estufa eléctrica. Papá dice que gasta demasiada energía y con el sueldo no le alcanza para mantenerla encendida todo el invierno. Me cubro con la frazada” (Skármeta, 2013, p. 28). Nico Santos se refiere al pantónimo narrativo que articula esta parte del relato con las siguientes palabras: "el clima sigue malo. La llovizna se nos impregna en los pómulos” (Skármeta, 2013, p. 77).

Los pormenores narrativos invernales descritos en estas escenas construyen, en palabras de Roland Barthes, efectos de realidad en sentido acumulativo (cit. en Pimentel, p. 63). Estos detalles entablan diálogo con los operadores tonales que decoran esta sección del relato, vale decir los colores que escoge el narrador para decorar episodios puntuales de la novela (Pimentel, p. 28). De esta manera, los objetos que acompañan al protagonista están coloreados con azul: "un par de compañeros me golpean en el hombro y me enrollo la bufanda azul en el cuello" (Skármeta, 2013, p. 41). El profesor Javier Valdivieso, docente que dicta clases de filosofía, porta prendas azules: "lleva anteojos [...] y un blazer azul lustroso" (Skármeta, 2013, p. 42). El profesor de educación física también es descrito con indumentarias azules: "sopla con un pito de árbitro cada vez que quiere que cambiemos el ritmo de nuestros saltos y piruetas. Debe sentirse bien dentro de su buzo azul” (Skármeta, 2013, p. 87).

Un muchacho vestido con un impermeable azul se acerca al grupo que encabeza Nico para entregar unas notas informativas de color celeste. Este documento, cuya tonalidad es afín con el azul, invita a manifestar el descontento estudiantil:

Al lado nuestro hay un chico de pelo largo e impermeable azul que nos llama la atención [...] De pronto saca del bolsón un montón de hojas y nos pasa una a cada uno del grupo.

[...]

La hoja celeste se titula «Acción» y contiene instrucciones para que nos tomemos el liceo en protesta por los profesores que han despedido. (Skármeta, 2013, pp. 77-8)

Los pormenores narrativos de índole invernal y los operadores tonales azules acuerdan una alianza descriptiva que asegura la legibilidad y la consistencia del relato. La siguiente referencia textual resuelve las implicancias de este contrato descriptivo: "Estamos en clase de dibujo. Recién la 
profesora nos explicó [...] que los colores provocan sensaciones, estados de ánimo. El azul es el más triste de todos. Es un color frío" (Skármeta, 2013, p. 133). Estos lineamientos estéticos son dispositivos que articulan los valores temáticos que sostienen la narración. Aspectos mínimos del relato cuya interacción facilita la identificación del lector con los episodios de violencia acontecidos en las escuelas chilenas durante la dictadura de Pinochet.

Los próximos capítulos de Los días del arcoíris retratan el asesinato del profesor Paredes. Los pormenores narrativos de estos episodios son provechosos para nuestros intereses, especialmente el farol que ilumina los acontecimientos y las marcas de violencia que registra el cuello de este docente:

Hemos llegado hasta el farol. [...] La gruesa lona tendida en el suelo cubre algo. El teniente le ordena con un ademán de la barbilla que la levante. El agente obedece desplegando la lona en toda su extensión. Es el cuerpo de un hombre. El profesor Paredes.

Sus ojos están cerrados y alrededor de su cuello tiene una o más sábanas manchadas de sangre.

-Degollado -le dice el hombre de la escarapela al teniente Bruna. (Skármeta, 2013, p. 147)

El farol que ilumina el espacio diegético es un registro del poder totalitario. Visibilizar el cuerpo del profesor degollado es una estrategia de la dictadura que pretende mostrar a la ciudadanía el funcionamiento de la maquinaria punitiva, pues, en palabras de Foucault, "es preciso que [el pueblo] se atemorice; pero también [...] debe ser el testigo, como el fiador del castigo, porque debe hasta cierto punto tomar parte en él" (Foucault, 2002, p. 63). Francisco Tirado y Martín Mora comentan estas palabras de este filósofo, aportando que el poder libera "las cosas en el terreno de la visión, exponiéndolas ante la mirada, sustrayéndolas al secreto y la oscuridad para arrojarlas a la luz" (p. 19).

Las marcas de brutalidad que registra el cuello del profesor Paredes evocan un contexto histórico que subyace en los acontecimientos narrados. Estas señales de tortura remiten al asesinato del profesor Manuel Guerrero Ceballos, docente del Colegio Latinoamericano de Integración que fue degollado en marzo de 1985. Recordemos que el profesor Guerrero, junto con Santiago Nattino y Manuel Leónidas, fue secuestrado por la policía política 
de Pinochet para ser torturado y cruelmente asesinado. Manuel Guerrero Ceballos, hijo del profesor degollado, testimonia en Desde el túnel (1979) las circunstancias en que su padre fue ultimado:

Ese fue el último beso que le di a mi padre esa mañana de marzo. Como si se tratara de una novela policial, se lo llevaron [...]. Los buscamos todo el día, toda la noche, toda la mañana...

[...]

Nuevamente Carabineros de Chile detuvo el tránsito, esta vez para degollar a Santiago Nattino, a José Manuel Parada y a mi padre Manuel Guerrero. En el silencio de la madrugada se oyeron nítidamente los gritos apagados de estos tres seres despojados de cualquier atributo ciudadano [...] para que se desangraran y fuesen olvidados. (Guerrero, 2008, pp. 7-8)

De modo similar, Antonio Skármeta se refirió en El baile de la victoria ${ }^{14}$ (2003) a las atrocidades que perpetró la dictadura contra el gremio docente. La protagonista de esta novela, Victoria, recuerda las circunstancias en que su padre fue degollado:

[...] pensando siempre en lo mismo.

- ¿En qué?

- En mi padre.

- ¿Qué pasa con él?

- Cuando mi madre estaba embarazada de mí, la policía detuvo a mi padre en la puerta del colegio donde hacía clases. Todo el mundo pudo verlo. Los agentes actuaron con helicópteros y coches sin patente. Dos días después encontraron su cuerpo degollado en una acequia. Yo nací cinco meses más tarde.

- ¿Qué había hecho tu papá?

- Estaba contra la dictadura. (Skármeta, 2009, p. 47).

El narrador de Los días del arcoíris incorpora algunas catálisis en los actos fúnebres del profesor Paredes que son provechosos para nuestra lectura, puntualmente el ramillete de crisantemos que homenajea al docente fallecido: "Atrás del grupo, cargando una corona de crisantemos, va Pa-

${ }^{14}$ El director Fernando Trueba adaptó El baile de la victoria al cine. Este film fue seleccionado para representar a España en los Premios Oscar de 2009. 
tricia” (Skármeta, 2013, p. 159). El narrador reitera estos arreglos florales páginas más adelante: "Patricia Bettini sostiene la corona de crisantemos sin alzar la vista” (Skármeta, 2013, p. 161).

En una primera instancia podríamos pensar que los crisantemos puntualizados en el relato son ofrendas cuyo propósito es honrar al profesor Paredes. Si agudizamos la vista y consideramos la fascinación de Antonio Skármeta por el cine y el rock ${ }^{15}$ (Arenas y Olivares, 2001, p. 227) podemos suponer que tales ofrendas florales remiten a un contexto más complejo.

Los cineastas argentinos Pablo Osores, Roberto Testa y Nicolás Wainzelbaum dirigieron la película-documental Flores de septiembre (2010) ${ }^{16}$. Este film relata la detención y desaparición de unos estudiantes de la Escuela Carlos Pellegrini durante la dictadura argentina. Esta película se inicia y finaliza con la canción "Crisantemos" de Luis Alberto Spinetta. La última estrofa de esta composición relaciona a los estudiantes desaparecidos con la flor del crisantemo:

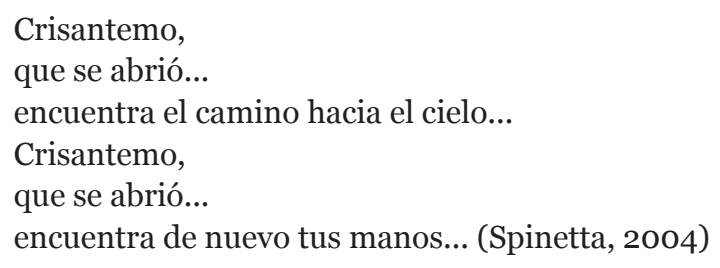

Las palabras que dirige el hablante lírico a los estudiantes argentinos desaparecidos podrían acompañar, sin problemas, los infortunios padecidos por el profesor Paredes en Los días del arcoíris. Esta referencia al cine y a la música demuestra que la elección floral del narrador skarmetiano no es gratuita, por el contrario, este pormenor narrativo está repleto de significación y sentido. Un detalle capaz de evidenciar los intereses del autor, a partir de un diálogo con otras producciones artísticas enmarcadas en los horrores perpetrados por las dictaduras militares que asolaron Latinoamérica.

${ }^{15}$ La fascinación de Skármeta por el rock se comprueba al revisar los epígrafes que el autor dispone en sus relatos. A modo de ejemplo, "Pescado" incorpora un fragmento de The Beatles; "El último tren" hace lo propio con un twist de Sergio Inostroza, etcétera.

${ }^{16}$ Flores de septiembre fue grabada en 2003 pero fue exhibida en 2010. 
En Los días del arcoíris se menciona la llegada de Héctor Barrios al Instituto Nacional, establecimiento educativo donde el protagonista cursa estudios secundarios. Este compañero, proveniente de Argentina, declara ser hijo de chilenos exiliados. La familia Barrios regresó a Chile luego que la dictadura levantó las prohibiciones de ingreso a los desterrados: “¿De dónde vienes? -le preguntó. - De Buenos Aires. Mi viejo estaba exiliado y le permitieron volver. Le sacaron la «L» del pasaporte" (Skármeta, 2013, p. 87).

Aquella «L» estampada en el pasaporte es un detalle que remite a las políticas migratorias que impuso Augusto Pinochet. El político Camilo Escalona, quien estuvo exiliado en Austria, se refiere a estas restricciones:

Aquella «L» fatídica que significaba «limitado», o sea, el contrasentido aberrante que la dictadura otorgaba un pasaporte en los consulados a quien fuera a pedirlo [...] pero con esa «L», que le permitía viajar por el mundo entero si quería, o mejor dicho, si podía, y que impedía ingresar a Chile. Un pasaporte chileno cuya única limitación era que no servía para viajar a Chile. Un monumento al más cruel maquiavelismo. (Escalona, 2012, p. 256)

En la novela de Skármeta los estudiantes que participan en el taller de teatro representan La cueva de Salamanca ${ }^{17}$. El narrador aprovecha esta instancia para evidenciar cómo operó la dictadura militar ${ }^{18}$ en las escuelas chilenas.

El Teniente Bruna dirige el Instituto Nacional en Los días del arcoíris. La autoridad castrense se dispone en primera fila para disfrutar la representación teatral de los alumnos: "Bruna mueve impaciente el pie de su pierna [...] y levanta la falda de su túnica púrpura de sacristán para secarse el sudor de la frente" (Skármeta, 2013, p. 130).

El color púrpura que viste el rector delegado es un operador tonal que exterioriza su jerarquía, ya que este color es símbolo de autoridad y domi-

${ }^{17}$ La cueva de Salamanca (1615) es un entremés escrito por Miguel de Cervantes.

${ }^{18} \mathrm{El}$ régimen militar intervino las unidades educativas del país, especialmente las Universidades tradicionales y los colegios emblemáticos. El Presidente Ricardo Lagos indica en sus memorias que la dictadura procedió a: "cerrar carreras [...] se congeló el ingreso (de personal) y, en general, se procedió a exonerar a una enorme proporción de los académicos [...]. Los centros universitarios de investigación donde había predominado el apoyo a la Unidad Popular, también fueron cerrados" (2014, p. 355). 
nio desde la antigüedad. Recordemos que el Imperio Mesopotámico reservó este matiz, junto con el oro, la plata y el estaño, a las clases más acomodadas (Fernández, 2010, pp. 32-3). De esta manera, el púrpura que decora la vestimenta de Bruna no es un color gratuito, por el contrario el narrador privilegió este matiz para reforzar la autoridad que ejerce este funcionario de la dictadura.

\section{Capítulos finales. Espacios de encuentro, alegría y fraternidad en el marco de la "estética risueña"}

Grínor Rojo señala que las tramas narrativas protagonizadas por Adrián Bettini y Nico Santos convergen en un mismo espacio narrativo en los capítulos finales de Los días del arcoíris. Este encuentro se posibilita en el marco de la "estética risueña", vale decir un recurso narrativo que restituye las esperanzas de un pueblo que, tras quince años en dictadura, no hubiese respondido de buena manera ante "un lenguaje que insistiera en la crueldad y el sufrimiento" (Rojo, 2016, p. 244).

Estos espacios de avecindamiento convocan pormenores narrativos afines a la "estética risueña", por ejemplo, las descripciones climáticas de esta parte del relato se oponen a los detalles invernales que fueron puntualizados en las secciones anteriores. De este modo, el "sol" y la "primavera" se instalan en el espacio diegético, una vez que los ciudadanos ejercen su derecho a voto en el marco del Plebiscito de 1988:

El día 5 de octubre ${ }^{19}$, Bettini llegó acompañado de Magdalena y Patricia hasta su local de votación cerca de plaza Egaña. Hizo la larga fila de votantes bajo un alegre sol comprándoles botellitas de agua mineral a los vendedores ambulantes. (Skármeta, 2013, p. 195)

Ya señalamos que el narrador privilegió el color azul en los episodios que protagonizó Nico Santos. Este privilegio cromático muestra un giro en los episodios finales de la novela, pues la "estética risueña" abre el relato a

\footnotetext{
${ }^{19}$ Efectivamente, los comicios del «No» se realizaron el 5 de octubre de 1988.
} 
una paleta multicolor. De esta manera, el color rojo se incorpora a la diégesis, a propósito del encuentro amoroso que sostienen Nico y Patricia, su novia. Esta muchacha acude a la cita vestida con una polera roja y los labios maquillados con "rojo furioso":

Hoy no viste (Patricia) el uniforme del colegio.

Trae en cambio una polera roja ceñida, directamente una talla más pequeña que las que usa.

[...]

Sus labios pintados de un rojo furioso combinan de maravilla con la polera. Es una boca que grita «bésame», «muérdeme». (Skármeta, 2013, p. 212)

A su vez, Nico Santos se presenta a la cita con una camisa blanca: "Me pone (Patricia) el pasaje en el bolsillo de la camisa blanca [...]. - Entonces, Nicómaco Santos, ia Valparaíso los boletos!" (Skármeta, 2013, p. 212).

La pareja de jóvenes arrienda una pieza en el puerto de Valparaíso para concretar el encuentro amoroso. Patricia se desplaza con el torso desnudo hasta la ventana y expresa lo siguiente: "yo soy esto. Es decir, si alguien me pintara y yo fuese un paisaje, sería de muchos colores...” (Skármeta, 2013, p. 220). La muchacha realiza esta declaración de cara a Valparaíso, es decir una urbe que convoca una diversidad de colores:

-Techos, tejas, muros amarillos, verdes, violetas, azules, granates, terracota, chimeneas, gaviotas, pelícanos, escaleras, peldaños, cables al alcance de la mano, ascensores que parecen casitas trepando por los rieles, los perros vagabundos, los volantines, y todo se sostiene apilado como si alguien lo hubiera puesto así al lote, dejándolo todo para más tarde. (Skármeta, 2013, p. 220)

Las últimas páginas de la novela describen la ceremonia de titulación de Nico Santos. A diferencia de los crisantemos dispuestos en los ritos fúnebres del profesor Paredes, en esta oportunidad los ramilletes que decoran el espacio diegético convocan toda una diversidad floral: "en el umbral del salón de acto hay una corona de rosas blancas, follaje de plantas verdes y algunos claveles rojos" (Skármeta, 20131, p. 227).

La ubicación espacial de Nico Santos durante la ceremonia también es 
significativa. El publicista Bettini se encarga de localizar al estudiante entre todos los muchachos que son homenajeados: “¿Cuál de esos chicos de arriba es su yerno? El pelucón de la izquierda con una corbata verde y azul" (Skármeta, 2013, p. 230). Estimamos que el narrador ubicó a Santos en el ala izquierda del relato para proyectar sobre la diégesis el ordenamiento visual del espectro político. Este pormenor narrativo subraya la identificación del protagonista con los sectores militantes de izquierdas contrarios a la dictadura de Pinochet.

El pelo alborotado de los egresados es un rasgo descriptivo que exterioriza la rebeldía de los jóvenes: "Los chicos se ven raros con traje y corbata. Todos tienen demasiado pelo alborotado para esa formalidad" (Skármeta, 2013, p. 228). Las cabelleras de los festejados sólo fueron posibles tras la conquista de la democracia, pues, en dictadura, los militares se encargaron de disciplinar las apariencias de los ciudadanos. Así lo recuerda Jorge Montealegre, prisionero político durante el régimen de Pinochet:

En una de esas caminatas me llevé un gran susto. En una esquina los soldados me detienen y me amenazan con cortarme el pelo con una bayoneta. Prometí que me lo cortaría ese mismo día para que me soltaran. El pelo largo, de hippie o guerrillero, para los milicos era un síntoma de indisciplina, desorden y relajo moral. Había que cortarlo violentamente. (Montealegre, 2003, pp. 24-5)

Los atuendos que viste Nico en la ceremonia de graduación aportan información relevante, especialmente su corbata: "palpa el nudo de la corbata verde con lunares azules que [...] ha conseguido prestada" (Skármeta, 2013, p. 225). El narrador pinta con verde la corbata del protagonista para proyectar instancias de futuro sobre las páginas finales de la novela, mientras que los lunares azules remiten a las atrocidades padecidas por el pueblo chileno durante la dictadura. La combinación de estos operadores tonales, en un mismo pormenor narrativo, contextualiza los últimos párrafos de Los días del arcoíris, puntualmente aquellas líneas en que Bettini señala lo siguiente: "la pugna entre el «Sí» y el «No» va a permanecer mucho tiempo [...]. Yo no me voy a olvidar nunca de lo que pasó". (Skármeta, 2013, pp. 233-4). 


\section{Palabras finales}

Nuestra lectura de Los días del arcoíris comprueba que la diégesis es un espacio ficticio donde el poder ejerce un dominio disciplinante. De este modo, señalamos que el poder se palpa en aspectos tan ínfimos como las prendas que visten los personajes, el largo de sus cabellos, los objetos que decoran el espacio, los colores que pintan el relato, entre otros aspectos. El narrador skarmetiano no pretende reflejar especularmente la sociedad chilena de 1988, sino que busca retratar los mecanismos disciplinarios y sus efectos sobre los imaginarios sociales. Los pormenores narrativos que se describen en Los días del arcoíris despliegan el estricto recetario que elaboró el régimen militar para construir ciudadanos dóciles y útiles a su proyecto de nación.

Los pormenores narrativos de Los días del arcoíris son unidades que precisan la contingencia histórica de una época desde la mirada de un novelista. El narrador skarmetiano procede a seleccionar declaraciones, nombres, antecedentes migratorios, entre otros aspectos, para contextualizar las circunstancias históricas del Plebiscito de 1988. En este sentido, Antonio Skármeta realiza una tarea similar a la del historiador, pues privilegia ciertas tramas discursivas para contar su "verdad".

En definitiva, los pormenores narrativos son recursos descriptivos que constituyen señales e indicios de un contexto literario, histórico, político e ideológico que subyace en los acontecimientos narrados.

\section{Referencias}

Arenas, Rogelio y Olivares, Gabriela. (2001). La voz a ti debida; conversaciones con escritores mexicanos. México: Universidad Autónoma de baja California.

Barthes, Roland. (1987). El efecto de realidad. El susurro del lenguaje. Más allá de la palabra y la escritura. Madrid: Paidós, 179-187.

Bentham, Jeremías. (1989). El panóptico. Madrid: La Piqueta.

Durán, Sergio. (2012). Ríe cuando todos estén tristes. El entretenimiento televisivo bajo la dictadura de Pinochet. Santiago: LOM.

Epple, Juan. (1983). El contexto histórico-generacional de la literatura de Antonio Skármeta. Del cuerpo a las palabras: la narrativa de Antonio Skármeta. Madrid: LAR, 101-115. 
Escalona, Camilo. (2012). De Allende a Bachelet: una vida política. Santiago: Aguilar.

Fernández, Pilar. (2010). Púrpura. Del mercado al poder. Madrid: Uned.

Foucault, Michel. (2002). Vigilar y castigar. Nacimiento de la prisión. Buenos Aires: Siglo veintiuno.

Guerrero, Manuel. (2008). Desde el túnel. Diario de vida de un detenido desaparecido. Santiago: LOM.

Huneeus, Carlos. (2000). El régimen de Pinochet. Santiago: Sudamericana.

Lagos, Ricardo. (2014). Mi vida. De la infancia a la lucha contra la dictadura. Santiago: Penguin random house grupo editorial.

Lozano, Jorge. (2008). Camuflaje: una estrategia de disimulación. Revista de Occidente, (330), 5-6.

Montealegre, Jorge. (2003). Frazadas del Estadio Nacional. Santiago: LOM.

O.S. (jun. 3, 2011). Los días del arcoíris. Cosas. Santiago: Chile, 162.

Pimentel, Luz. (2001). El espacio en la ficción. Buenos Aires: Siglo Veintiuno. Editores.

Piña, Juan. (1991). Conversaciones con la narrativa chilena. Santiago: Los Andes.

Rojo, Grínor. (2016). Ficción e historia en Los días del arcoíris de Antonio Skármeta. Revista chilena de literatura, (92), 233-249.

Skármeta, Antonio. (1985). Ardiente paciencia. Buenos Aires: Sudamericana.

- (1989). No pasó nada. Santiago: Pehuén.

. (2009). El baile de la victoria. Santiago: Planeta.

. (2013). Los días del arcoíris. Santiago: Planeta.

Spinetta, Luis Alberto. (2004). Crisantemo. Camalotus [EP]. Buenos Aires: Universal music.

Soto, Marcelo. (2013). Skármeta y la chispa del No. Capital, (341), 26-28. Tirado, Francisco y Mora, Martín. (2002). El espacio y el poder: Michael Foucault y la crítica de la historia. Espiral. Estudios sobre Estado y Sociedad, (25), 11-36.

White, Hayden. (1992). Metahistoria. La imaginación histórica en la Europa del siglo XIX. México: Fondo de cultura económica. . (2003). El texto histórico como artefacto literario. Barcelona: Paidós, 107-139. 